\title{
Assessing Racial/Ethnic and Gender Gaps in Political Science PhD Students' Methodological Self-Efficacy
}

Amy Erica Smith, Iowa State University, USA

Shauna N. Gillooly, American Council of Learned Societies, USA

Heidi Hardt, University of California, Irvine, USA

ABSTRACT Most research on diversity within political methodology focuses on gender while overlooking racial and ethnic gaps. Our study investigates how race/ethnicity and gender relate to political science $\mathrm{PhD}$ students' methodological self-efficacy, as well as their general academic self-efficacy. By analyzing a survey of 300 students from the top 50 US-based political science $\mathrm{PhD}$ programs, we find that race and ethnicity correlate with quantitative self-efficacy: students identifying as Black/African American and as Middle Eastern/North African express lower confidence in their abilities than white students. These gaps persist after accounting for heterogeneity among $\mathrm{PhD}$ programs, professional and socioeconomic status, and preferred methodological approach. However, small bivariate gender gaps disappear in multivariate analysis. Furthermore, gaps in quantitative self-efficacy may explain racial/ethnic disparities in students' broader academic self-efficacy. We argue that the documented patterns likely lead to continued underrepresentation of marginalized groups in the political methodology student body and professoriate.

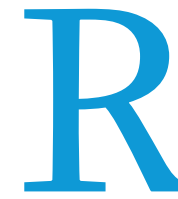

ecruiting and retaining a diverse workforce is a persistent challenge in academia. Within political science, this difficulty has been particularly pronounced in the political methodology subfield. As Methodology faces severe diversity challenges" (Hidalgo et al. 2018 , 1). Not only is the percentage of women in the political methodology section the lowest among all American Political Science Association (APSA) organized sections; the section also is markedly less racially and ethnically diverse than APSA as a

Amy Erica Smith (D) is associate professor as well as Carnegie Fellow and Liberal Arts and Sciences Dean's Professor at Iowa State University. She can be reached at aesmith2@iastate.edu.

Shauna N. Gillooly (iD) is a postdoctoral fellow for the American Council of Learned Societies Leading Edge Program. She can be reached at sgillool@uci.edu.

Heidi Hardt (D) is associate professor of political science at the University of California, Irvine, and Council on Foreign Relations International Affairs Fellow. She can be reached at www.heidihardt.com. whole. For instance, whereas $4.5 \%$ of APSA membership identifies as Black or African American, the analogous percentage in the political methodology section is only 1.3\% (Hidalgo et al. 2018).

Whereas the stark facts of both gender and racial/ethnic underrepresentation in political methodology are well understood, most relevant research explores and explains gender diversity. Numerous recent studies of gender inequalities have been published in leading journals, including both PS: Political Science \& Politics and Political Analysis (Brown and Samuels 2018; Dion, Sumner, and Mitchell 2018; Esaray and Bryant 2018; Murdie 2018; Peterson 2018; Sen 2018). By contrast, journals offer few empirical insights into the nature, causes, and consequences of racial and ethnic inequalities.

This article investigates racial/ethnic and gender gaps in political science $\mathrm{PhD}$ students' attitudes toward political methodology. Our primary research question was: How are race and ethnicity related to students' methodological self-efficacy as well as their general academic self-efficacy? Secondarily, our study allowed us to assess gender gaps in these attitudes. To answer these questions, we 
analyzed an original survey of 300 students enrolled in the top $50 \mathrm{PhD}$ programs in political science in the United States. Our broader project explored mentorship, role models, and diversity in political methodology and more generally in political science (Gillooly, Hardt, and Smith 2021). This article discusses responses to survey questions concerning students' interest and self-efficacy with respect to qualitative and quantitative methods, as well as their academic success by affecting an individual's decision to undertake new activities with uncertain outcomes and to persist in the face of initial difficulties or temporary failures. Indeed, prior research found that self-efficacy strongly predicts performance in educational contexts (Pajares 1996; Schunk 1989). Within doctoral programs, research-related self-efficacy may affect engagement in research and dissertation completion (Baltes et al. 2010; Bieschke,

\section{Whereas the stark facts of both gender and racial/ethnic underrepresentation in political methodology are well understood, most of the relevant research explores and explains gender diversity.}

academic careers more generally. Given the predominance of quantitative over qualitative research in top political science journals, we focused primarily on attitudes toward the former. We expected students' perceptions of their quantitative skills to influence their actual and self-perceived prospective academic success more strongly than their qualitative skills.

Our results are as follows. First, we found sizable racial/ethnic differences in respondents' attitudes toward their own success. Students who identified as Middle Eastern/North African (MENA) or as Black/African American reported substantially lower selfefficacy in quantitative methods than white students. We considered various explanations for the racial/ethnic gaps, including $\mathrm{PhD}$ program rank, unmeasured program effects, demographic factors, and differences in academic interests. However, none of these variables fully explained racial/ethnic gaps in quantitative efficacy.

Second, bivariate analysis revealed small gender gaps in quantitative efficacy, but those gaps disappeared in multivariate analysis. Nonetheless, there is evidence of intersectionality, although the evidence is inconclusive due to small sample sizes: gender gaps appear larger within certain racial/ethnic groups and racial/ethnic gaps appear more pronounced among women than among men.

Third, we discovered racial/ethnic disparities in students' broader evaluations of their present and future academic success, which appear to be strongly linked to previously documented gaps in students' quantitative self-efficacy.

Fourth, we found few other demographic and status-related correlates of self-efficacy, with two exceptions. Program rank mattered, and students with a partner expressed substantially higher academic self-efficacy than single students. This latter relationship was found across male and female students as well as those with and without dependents.

\section{SELF-EFFICACY, GRADUATE TRAINING, AND REPRESENTATION}

In Bandura's $(1982,122)$ classic formulation, "self-efficacy" refers to "judgments of how well one can execute courses of action required to deal with prospective situations." Hence, self-efficacy is domain specific, requiring an evaluation of oneself, of the task in question, and of the broader context. This article is concerned with two forms of student self-efficacy: the perceived ability to (1) perform effective quantitative analysis, and (2) succeed in an academic career more broadly.

Self-efficacy evaluations are not neutral; rather, as Bandura $(1982,123)$ argued, they constitute "one set of proximal determinants of how people behave." That is, self-efficacy impacts student
Bishop, and Garcia 1996; Varney 2010). Among Black students in particular, self-efficacy is a critical predictor of academic progress and science achievement (Dortch 2016; Reid 2013; Tate et al. 2015; White, DeCuir-Gunby, and Kim 2019). Within political science, we expect methodology to be a critical area for building student selfefficacy because methods constitute a central skill for a wide variety of research tasks and because this area of teaching arouses high levels of student anxiety (Bos and Schneider 2009; Murphy 2015).

Because these judgments require multidimensional evaluations of self, task, and context, several forces shape self-efficacy. Prior educational encounters may affect a student's actual and self-perceived skills and preparation for a given academic task. They also create a stock of experiences that influence judgments about a student's likelihood of success in analogous future tasks. In addition, contextual factors such as exposure to professional role models from within a student's own identity group (e.g., female professors and researchers of color) may affect self-efficacy. Exposure to these role models might affect assessments of a student's own capabilities as well as the likely response of the external environment to members of a student's group.

Thus, doctoral students' self-efficacy might vary by race, ethnicity, and gender. Not only do those demographic identities correlate with their own grade-school and undergraduate educational experiences; exposure to in-group academic role models also varies by race, ethnicity, and gender. Indeed, in at least one study, the political science curriculum has been shown to widen gaps in self-efficacy by race and ethnicity (Centellas and Rosenblatt 2018). Nonetheless, prior work found inconsistent and small gaps in self-efficacy between female and male students (Huang 2013; MacPhee, Farro, and Canetto 2013; Yorra 2014). This was perhaps in part due to the effects of female peer-mentoring during academic programs (Dennehy and Dasgupta 2017; MacPhee, Farro, and Canetto 2013). The following section investigates race/ethnic and gender gaps within the specific domain of political science $\mathrm{PhD}$ methodology training.

\section{METHODS AND ANALYSIS}

Our study proceeded as follows. In December 2019, we fielded an online survey via Qualtrics to students from the top $50 \mathrm{PhD}$ programs in the United States, according to the US News $\mathcal{E}$ World Report (2019). We emailed invitations to approximately two thousand students and offered a \$15 Amazon gift card for completing the survey. Given our budget limitations, we capped the survey administration at 300 students, despite additional interest. In total, 308 students began the survey and 297 completed it. Our sample is representative of the general membership of APSA on 
race and first-generation status (i.e., a marker of socioeconomic status).

Our key attitudinal variables were based on questions that asked students to rate, on a 1-to-5 scale, their "interest" and "ability" (i.e., self-efficacy) in quantitative and qualitative methods. In addition, we developed an index of general academic self-efficacy: the mean of eight items (alpha $=0.83$ ) asking students to evaluate their fit within their PhD program and their likely future success. These five variables were rescaled to run from o to 1 ; summary statistics are reported in the online appendix. In addition, we asked self-identified demographic questions related to race, gender, year in program, age, first-generation status, and whether the student had a partner (e.g., spouse or domestic partner) and/or dependents (e.g., children and elderly family members). Finally, we coded the rank of the student's PhD program based on the 2019 US News $\mathcal{E}$ World Report. To facilitate the interpretation of coefficients along with those for other independent variables, program rank was recoded to run from o to 1 ; higher values indicated "lower" or less prestigious rankings. Additional details on all items are in the online appendix (Smith, Gillooly, and Hardt 2021).

Our analysis had three phases. First, we assessed bivariate gaps in quantitative self-efficacy. Second, several multivariate hierarchical models accounted for various possible explanations of the demographic gaps that we uncovered. Third, we modeled general academic self-efficacy as a function of demographics and quantitative self-efficacy. All analysis used multilevel linear models to account for heterogeneity in the experiences of students in different $\mathrm{PhD}$ programs.

\section{RESULTS}

In our initial bivariate analysis, we found sizable racial/ethnic gaps in quantitative self-efficacy. At the high end, Latinos/as, whites, Asians, and students of "other" identifications all reported mean values between o.6o and 0.65. However, Black/African American students reported means of 0.48 and MENA students reported means of 0.41 . The gaps between the latter two racial/ ethnic groups and whites, Asians, and other students were all statistically significant at $p<0.10$ or lower. Figure $\mathrm{S}_{1}$ in the online appendix displays distributions that are substantially left-skewed among Black/African American and MENA students relative to those among white and Asian students-and, to a lesser extent, Latinos/as.

We also discovered small gender gaps in this orientation. Whereas men reported mean values of 0.65 , women reported $0.59(p=0.05)$, and students identifying as other or nonbinary reported 0.55 ( $p=0.46$ for the male-nonbinary gap). It is interesting that gender and race/ethnicity appear to have interactive or intersectional effects. The online appendix reveals major racial/ ethnic gaps among women but minor gaps among men; similarly, gender gaps appear to be limited to certain racial/ethnic groups. Nonetheless, only one of the interactions meets standard levels of statistical significance. Given the small sample sizes, the remainder of this article focuses on main effects.

In the second phase of analysis, we developed multivariate hierarchical models of quantitative self-efficacy, controlling for personal demographics that might impact students' math preparation (e.g., status as a first-generation college student). We also accounted for department-level effects in two ways: through the use of hierarchical linear models and by controlling for program rank. ${ }^{2}$ To summarize our key findings, gender gaps decreased and became statistically insignificant but racial/ethnic gaps remained substantial and statistically significant, even slightly increasing relative to the bivariate results. As shown in figure 1, predicted quantitative efficacy was 0.42 for MENA students and 0.46 for Black/African American students compared with 0.63 for whites, 0.61 for Latinos/as, and 0.67 for Asians. MENA students' quantitative self-efficacy was

\section{Figure 1}

Conditional Means of Quantitative Self-Efficacy, by Race/Ethnicity

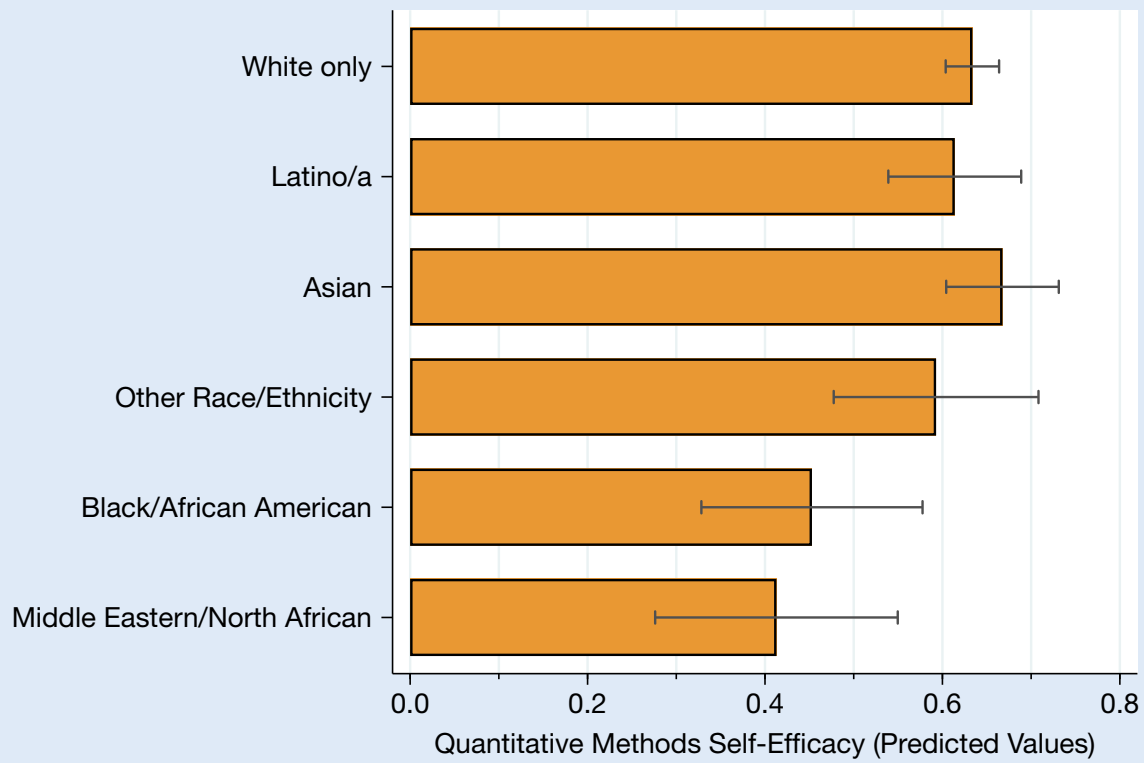


Table 1

Determinants of General Academic Self-Efficacy (Hierarchical Linear Models)

(1)

\begin{tabular}{|c|c|c|c|c|}
\hline & Coefficient & Standard Error & Coefficient & Standard Error \\
\hline Quantitative Methods Self-Efficacy & & & $0.20 * * *$ & 0.05 \\
\hline Quantitative Methods Interest & & & 0.04 & 0.04 \\
\hline Qualitative Methods Self-Efficacy & & & 0.05 & 0.05 \\
\hline Qualitative Methods Interest & & & 0.02 & 0.04 \\
\hline Middle Eastern/North African & $-0.15^{* *}$ & 0.06 & -0.08 & 0.06 \\
\hline Black/African American & $-0.09 *$ & 0.06 & -0.05 & 0.05 \\
\hline Other Race & -0.06 & 0.05 & -0.04 & 0.05 \\
\hline Asian & -0.03 & 0.03 & -0.04 & 0.03 \\
\hline Latino/a & -0.01 & 0.03 & -0.01 & 0.03 \\
\hline Female & -0.01 & 0.02 & -0.01 & 0.02 \\
\hline Other/Nonbinary Gender & 0.08 & 0.10 & 0.11 & 0.09 \\
\hline Year in Program & 0.00 & 0.01 & 0.00 & 0.01 \\
\hline Age 26-29 & 0.01 & 0.03 & -0.01 & 0.03 \\
\hline Age 30-35 & -0.01 & 0.03 & -0.03 & 0.03 \\
\hline Age $36-45$ & -0.02 & 0.05 & -0.03 & 0.05 \\
\hline First-Generation Student & 0.01 & 0.03 & 0.00 & 0.02 \\
\hline Has Dependents & -0.27 & 0.17 & -0.21 & 0.17 \\
\hline Has Partner & $0.06^{* * *}$ & 0.02 & $0.06^{* * *}$ & 0.02 \\
\hline Has Dependents X Has Partner & 0.26 & 0.17 & 0.21 & 0.17 \\
\hline Rank of PhD Program (0-1 Scale) & $-0.08 * *$ & 0.03 & -0.04 & 0.03 \\
\hline Constant & $0.74 * * *$ & 0.03 & $0.54 * * *$ & 0.05 \\
\hline Number of Observations & 285 & & 285 & \\
\hline R-Squared (Within) & 0.07 & & 0.16 & \\
\hline$R$-Squared (Overall) & 0.10 & & 0.20 & \\
\hline
\end{tabular}

Notes: Dependent variable is scaled to run from 0 to 1 . The baseline categories are male, white, and aged $21-25 .{ }^{*} p<0.10 ;{ }^{* *} p<0.05 ;{ }^{* *} p<0.01$.

approximately one standard deviation below that of Asian and white students. The full model is presented and discussed in the online appendix.

In further analysis (see the online appendix), we investigated racial/ethnic gaps in other methodological attitudes. MENA students reported substantially lower interest in quantitative methods than any other group, but Black/African American students reported having the same interest in quantitative methods as white, Latino/a, and Asian students. It is important to note that we found only a weak relationship between race/ethnicity and attitudes toward qualitative methods. ${ }^{3}$ In our results, women and men did not differ significantly in their interest in quantitative methods; however, women expressed substantially higher efficacy and interest with respect to qualitative methods.

The direction of causality among quantitative self-efficacy and methodological orientations is unclear; interest likely shapes perceived abilities and vice versa. Nonetheless, a model of quantitative efficacy controlling for the other orientations is developed in the online appendix. A sizeable gap in quantitative methods self-efficacy remains between Black/African American students and members of other racial/ethnic groups. However, the gap between MENA and other students decreased by more than $75 \%$ and no longer reaches standard levels of statistical significance.
In the third phase of analysis, we investigated whether racial/ ethnic gaps in quantitative efficacy were related to students' general academic self-efficacy. The first model in table 1 displays gaps in academic self-efficacy by race similar to-albeit smaller than-those found for quantitative self-efficacy. In the second model, we introduced controls for methodological orientations. Of the four attitudes, only quantitative self-efficacy was significantly correlated with general academic self-efficacy; it is the single strongest predictor of general academic self-efficacy. In this model, racial/ethnic gaps in general self-efficacy were substantially reduced in magnitude and no longer reached standard levels of statistical significance.

In addition to racial and ethnic identification, two other variables correlate with general academic self-efficacy: program rank and partner status. ${ }^{4}$ It is important to note that women, men, and students with other gender identifications all expressed similar levels of efficacy; likewise, first-generation students expressed efficacy similar to their peers. It is intriguing that having dependents (e.g., children) also was not significantly correlated with this measure for those either with or without a partner. (However, single parents may have lower efficacy than other single students; $p<0.11$ in model 1.) The coefficient for the variable for partnership was larger in follow-up analyses limited to women than those 
limited to men, although differences between the two genders were not statistically significant.

\section{DISCUSSION AND CONCLUSION}

In summary, our results reveal substantial racial and ethnic gaps in quantitative self-efficacy. It is important to note that these gaps are not attributable to covarying demographics or to program
Doctoral programs remain racialized institutions (Posselt 2018), and $\mathrm{PhD}$ student satisfaction varies significantly by race (Ong et al. 2011; Slay, Reyes, and Posselt 2019). Black female, Latino, and Latina graduate students report receiving less effective mentorship and being more likely to experience racism than other students (Johnson-Bailey 2004; Monforti and Michelson 2008). Many students of color feel that opportunities continue to be

\section{...Identification as Black/African American versus white is associated with a larger reduction in quantitative self-efficacy than attending a 5oth-ranked versus a first-ranked PhD program.}

characteristics. Whereas gaps between MENA and white students also appeared in their interest in quantitative methods, the Black/ African American-white gap did not extend to academic interests. Controlling for attitudes toward other methods (see online appendix table $\mathrm{S}_{5}$ ), only Black racial identification and program rank significantly predicted quantitative methods self-efficacy. In that model, it is worth noting that the coefficient of Black racial identification (i.e., -o.18) was substantially larger than that for program rank (i.e., -0.11). In other words, identification as Black/ African American versus white is associated with a larger reduction in quantitative self-efficacy than attending a 5oth-ranked versus a first-ranked $\mathrm{PhD}$ program. We show that these gaps have significant downstream consequences for general academic selfefficacy. They also likely affect subsequent retention in the political methodology workforce.

To the best of our knowledge, our analysis of racial and ethnic gaps in the field of political methodology is novel. As a result, we cannot confirm whether our results would replicate in other samples of $\mathrm{PhD}$ students in this or related disciplines. We also are unable to draw on prior evidence to elucidate the mechanisms underlying the gaps that we uncovered. Instead, most of our findings relate to our failure to explain racial/ethnic gaps. denied them due to structural racism within the academy (BauerWolf 2017; Eisenkraft 2010). These experiences ultimately contribute to higher attrition rates among $\mathrm{PhD}$ students of color. Moreover, these experiences persist even after achieving a tenuretrack position. Faculty of color report mistreatment from colleagues due to a racial stereotype of "presumed incompetence" (Gutiérrez y Muhs et al. 2012). Recently, many Black scholars shared related experiences on Twitter (e.g., \#BlackintheIvory, created by Dr. Shardé M. Davis).

Consequently, our research has significant implications for political science at a time when departments are seeking to become more diverse and inclusive. As long as students of color continue to express these feelings of marginalization, political science likely will struggle with attrition. Numerous diversity initiatives can reduce inequities. Faculty can diversify syllabi by using existing professional databases (e.g., "People of Color Also Know Stuff") to include role models for students of color. Institutions can develop programs to mentor and support undergraduates of color preparing for $\mathrm{PhD}$ programs as well as entering firstyear PhD students (e.g., the Ralph Bunche Summer Institute, APSA mentorship program, and Competitive Edge program at numerous University of California campuses). Departments can

\section{To the best of our knowledge, our analysis of racial and ethnic gaps in the field of political methodology is novel. As a result, we cannot confirm whether our results would replicate in other samples of PhD students in this or related disciplines. We also are unable to draw on prior evidence to elucidate the mechanisms underlying the gaps that we uncovered. Instead, most of our findings relate to our failure to explain racial/ethnic gaps.}

Unfortunately, our survey did not ask about students' undergraduate education or training (e.g., whether they studied outside of the United States), which could be a relevant explanation for our findings concerning MENA students. However, we do note that students with international undergraduate degrees are found in many different racial/ethnic groups. Future academic research is needed to replicate our findings and search for potential alternative explanations.

Our findings advance a broader body of research on racial disparities in academia. Gaps in self-efficacy might result in part from a dearth of diverse role models in the professoriate at the same time that these gaps perpetuate future underrepresentation. educate faculty to reduce racial biases in the classroom. Ultimately, scholars have a clear interest in retaining the best potential minds in research-irrespective of their racial identity.

\section{DATA AVAILABILITY STATEMENT}

Research documentation and data that support the findings of this study are openly available at the PS: Political Science \& Politics Dataverse at https://doi.org/10.7910/DVN/C5FOW7.

\section{SUPPLEMENTARY MATERIALS}

To view supplementary material for this article, please visit http:// dx.doi.org/10.1017/S1049096521001116. 


\section{NOTES}

1. The study was certified as exempt by the Institutional Review Boards of Iowa State University (ID 19-502) and University of California, Irvine.

2. In baseline hierarchical models, the department level accounts for $12 \%$ of the error variance.

3. MENA students reported slightly but not significantly lower qualitative methods self-efficacy. This white-MENA gap reaches standard levels of statistical significance in one of the multivariate models reported in the online appendix.

4. Of the variables discussed in this paragraph, only program rank correlates significantly with quantitative methods self-efficacy (see online appendix table S4).

\section{REFERENCES}

Baltes, Beate, Peter Hoffman-Kipp, Laura Lynn, and Lisa Weltzer-Ward. 2010. "Students' Research Self-Efficacy During Online Doctoral Research Courses." Contemporary Issues in Education Research 3 (3): 51-58.

Bandura, Albert. 1982. "Self-Efficacy Mechanism in Human Agency." American Psychologist 37 (2): 122-47.

Bauer-Wolf, Jeremy. 2017. “Big Brother: College Edition.” Washington, DC: Inside Higher Ed. www.insidehighered.com/news/2017/12/21/georgia-techs-monitoringstudentssocial-media-causes-concern.

Bieschke, Kathleen J., Rosean M. Bishop, and Victoria L. Garcia. 1996. "The Utility of the Research Self-Efficacy Scale." Journal of Career Assessment 4 (1): 59-75.

Bos, Angela L., and Monica C. Schneider. 2009. "Stepping around the Brick Wall: Overcoming Student Obstacles in Methods Courses.” PS: Political Science \& Politics 42 (2): $375-83$.

Brown, Nadia E., and David Samuels. 2018. "Beyond the Gender Citation Gap: Comments on Dion, Sumner, and Mitchell." Political Analysis 26 (3): 328-30.

Centellas, Miguel, and Cy Rosenblatt. 2018. "Do Introductory Political Science Courses Contribute to a Racial 'Political Efficacy Gap'? Findings from a Panel Survey of a Flagship University." PS: Political Science \& Politics 51 (3): 641-47.

Dennehy, Tara C., and Nilanjana Dasgupta. 2017. "Female Peer Mentors Early in College Increase Women's Positive Academic Experiences and Retention in Engineering." Proceedings of the National Academy of Sciences 114 (23): 5964-69. DOI:10.1073/pnas.1613117114.

Dion, Michelle L., Jane L. Sumner, and Sara M. Mitchell. 2018. "Gendered Citation Patterns across Political Science and Social Science Methodology Fields." Political Analysis 26 (3): 312-27.

Dortch, Deniece. 2016. "The Strength from Within: A Phenomenological Study Examining the Academic Self-Efficacy of African American Women in Doctoral Studies." Journal of Negro Education 85 (3): 350-64.

Eisenkraft, Harriet. 2010. "Racism in the Academy." University Affairs 51 (9): 12-19.

Esarey, Justin, and Kristin Bryant. 2018. "Are Papers Written by Women Authors Cited Less Frequently?" Political Analysis 26 (3): 331-34.

Gillooly, Shauna, Heidi Hardt, and Amy Erica Smith. 2021. "Having Female Role Models Correlates with PhD Students' Attitudes Toward Their Own Academic Success." PLOS ONE 16 (8):e0255095. DOI:10.1371/journal.pone.0255095.

Gutiérrez y Muhs, Gabrielle, Yolanda F. Niemann, Carmen G. González, and Angela P. Harris (eds.). 2012. Presumed Incompetent: The Intersections of Race and Class for Women in Academia. Boulder: University Press of Colorado.

Hidalgo, F. Daniel, Suzanna Linn, Margaret Roberts, Betsy Sinclair, and Rocío Titiunik. 2018. "Report on Diversity and Inclusion in the Society for Political Methodology." Cambridge University Press: Society for Political Methodology, $1-33$.
Huang, Chiungjung. 2013. "Gender Differences in Academic Self-Efficacy: A MetaAnalysis." European Journal of Psychology of Education 28 (1): 1-35.

Johnson-Bailey, Juanita. 2004. "Hitting and Climbing the Proverbial Wall: Participation and Retention Issues for Black Graduate Women." Race Ethnicity and Education 7 (4): 331-49.

MacPhee, David, Samantha Farro, and Silvia Sara Canetto. 2013. "Academic SelfEfficacy and Performance of Underrepresented STEM Majors: Gender, Ethnic, and Social Class Patterns." Analyses of Social Issues and Public Policy 13 (1):347-69.

Monforti, Jessica Lavariega, and Melissa R. Michelson 2008. "Diagnosing the Leaky Pipeline: Continuing Barriers to the Retention of Latinas and Latinos in Political Science." PS: Political Science \& Politics 41 (1): 161-66.

Murdie, Amanda. 2018. "We Need a New International Norm: Eradicating the Gender Citation Gap." Political Analysis 26 (3): 345-47.

Murphy, Chad. 2015. "The Use of Peer Modeling to Increase Self-Efficacy in Research Methods Courses." Journal of Political Science Education 11 (1): 78-93.

Ong, Maria, Carol Wright, Lorelle L. Espinosa, and Gary Orfield. 2011. "Inside the Double Bind: A Synthesis of Empirical Research on Undergraduate and Graduate Women of Color in Science, Technology, Engineering, and Mathematics." Harvard Educational Review 81 (2): 172-209.

Pajares, Frank. 1996. "Self-Efficacy Beliefs in Academic Settings." Review of Educational Research 66 (4): 543-78.

Peterson, David A. M. 2018. "Historical Disparities and Gendered Citation Patterns." Political Analysis 26 (3): 338-44

Posselt, Julie R. 2018. "Rigor and Support in Racialized Learning Environments: The Case of Graduate Education.” New Directions for Higher Education 181:59-70.

Reid, Karl W. 2013. "Understanding the Relationships among Racial Identity, SelfEfficacy, Institutional Integration, and Academic Achievement of Black Males Attending Research Universities." Journal of Negro Education 82 (1): 75-93.

Schunk, Dale H. 1989. "Self-Efficacy and Achievement Behaviors." Educational Psychology Review 1 (3): 173-208.

Sen, Maya. 2018. "Response to Dion, Sumner, and Mitchell." Political Analysis 26 (3) 335-37.

Slay, Kelly E., Kimberly A. Reyes, and Julie R. Posselt. 2019. "Bait and Switch: Representation, Climate, and Tensions of Diversity Work in Graduate Education." Review of Higher Education 42 (5): 255-86.

Smith, Amy Erica, Shauna Gillooly, and Heidi Hardt. 2021. "Replication Data for: Assessing Racial/Ethnic and Gender Gaps in Political Science PhD Students' Methodological Self-Efficacy." Harvard Dataverse https://doi.org/10.7910/DVN/ $\mathrm{C}_{5} \mathrm{FOW}_{7}$.

Tate, Kevin A., Nadya A. Fouad, Laura Reid Marks, Gary Young, Eddie Guzman, and Eric G. Williams. 2015. "Underrepresented First-Generation, Low-Income College Students' Pursuit of a Graduate Education: Investigating the Influence of SelfEfficacy, Coping Efficacy, and Family Influence." Journal of Career Assessment $23(3): 427-41$.

U.S. News \& World Report. 2019. "Best Political Science Schools." www.usnews.com/ best-graduate-schools/top-humanities-schools/political-science-rankings. Accessed August 5, 2019.

Varney, James J. 2010. “The Role of Dissertation Self-Efficacy in Increasing Dissertation Completion: Sources, Effects, and Viability of a New Self-Efficacy Construct." College Student Journal 44 (4): 932-48.

White, Angela M., Jessica T. DeCuir-Gunby, and Seongtae Kim. 2019. "A Mixed Methods Exploration of the Relationships between the Racial Identity, Science Identity, Science Self-Efficacy, and Science Achievement of African American Students at HBCUs." Contemporary Educational Psychology 57 (April): 54-71.

Yorra, Mark L. 2014. "Self-Efficacy and Self-Esteem in Third-Year Pharmacy Students." American Journal of Pharmaceutical Education 78 (7): 134 